\title{
EFFECT OF POSTER AND VIDEO INTERVENTION ON THE KNOWLEDGE, ATTITUDE AND PRACTICE (KAP) LEVEL OF PERSONAL HYGIENE AMONG FOOD HANDLERS IN 24 HOURS MAMAK RESTAURANTS IN SUNGAI PETANI, KEDAH
}

\author{
M. Masyita ${ }^{1}$, M. J. N. Amalina ${ }^{1}$, A. S. M. Saudi ${ }^{1,}{ }^{*}$, M. S. Samsudin ${ }^{2}$ and Z. I. $\operatorname{Rizman}^{3}$ \\ ${ }^{1}$ Institute of Medical Science and Technology, University of Kuala Lumpur, 43600 Kajang, \\ Selangor, Malaysia \\ ${ }^{2}$ Faculty of Bioresources and Food Industry, Universiti Sultan Zainal Abidin, 22200 Besut, \\ Terengganu, Malaysia \\ ${ }^{3}$ Faculty of Electrical Engineering, UniversitiTeknologi MARA, 23000 Dungun, Terengganu, \\ Malaysia
}

Published online: 05 October 2017

\begin{abstract}
This study assesses the knowledge, attitude and practice on personal hygiene among food handlers at 24 hours Mamak operation restaurants before and after poster and video intervention. A survey and observation checklist was conducted among 100 food handlers selected from Mamak restaurants. 77\% of respondents were aware on personal hygiene during the pre-intervention and the percentage has slightly escalated to $100 \%$ after intervention. Similarly, the percentage of good personal hygiene practice was increase after the intervention ( $42 \%$ to $73 \%$ respectively). It was observed that there was no significant correlation between knowledge and practice $(\mathrm{r}=-0.082, \mathrm{p}=0.415)$, similarly there was no significant correlation observed between knowledge and attitude $(r=-0.009, p=0.930)$.
\end{abstract}

Author Correspondence, e-mail: ahmadshakir@unikl.edu.my

doi: http://dx.doi.org/10.4314/jfas.v9i4s.48 
The finding adds to the growing body of evidence on the effectiveness of poster and video intervention.

Keywords: KAP; poster and video intervention; personal hygiene; food handlers; 24 hours Mamak restaurants.

\section{INTRODUCTION}

Mamak culture or "frequenting a Mamak restaurant" has evolved and become a phenomenon in Malaysia. It is also believed that the Mamak culture inculcates values of national unity with providing a place where Malaysians and foreigners can come to relax, while enjoying great food and great conversation in a laid back environment. Consequently, this phenomenon has led to the increase operational hours of Mamak restaurants [1-3]. Having known on the culture of Mamak frequenting restaurants in Malaysia, several issue has risen in relation to the hygiene of food premise and food handling. Recently, one Mamak restaurant in Klang was ordered to close for failing to comply with hygiene requirements [4]. On the previous year, three Mamak restaurants in Selayang were ordered to close due to three major errors committed: the unused apron and hat, raw food on the floor and the food wastes stream down the drain [5]. Similarly, in all cases reported, the Mamak restaurants were found failed to control pests, especially cockroaches and rats [4-5].

The incidence raised a public concern on the operation of food handling in the Mamak restaurants. The mishandling of food during food preparation and serving may cause foodborne illness and this accounts $50 \%$ of the cases reported [6]. As part of the initiative, Ministry of Health, Malaysia has enforced all food handlers are required to undergo Food Handler trainings that are recognized by the Ministry of Health. The training comprised of the elements of food safety which include foodborne illness, food contamination, personal hygiene, food storage, cleaning and disposal practices and pest control [7]. Although the initiatives were taken by the $\mathrm{MOH}$, the incidence rate of foodborne illness has increased 3\% from the year 2012 to 2012 (44.79\% and 47.79\% respectively). The increase of foodborne illness indicates the food safety negligence among the food handlers [8]. In addition, the limited benefits derived from the food safety training were linked to the absence of disseminating knowledge and skill due to the lack of effective follow up monitoring and 
mentoring when trainees return to the workplace. In [9] also discussed that the training should not only prepare workers to perform appropriate safety behaviours, but also to identify and address barriers that prevent them from exhibiting these behaviours.

Previous research have shown that obtaining food safety certification is correlated with higher food safety knowledge among foodservice workers or managers [10-12], however those managers with little to no knowledge of national language or English or limited reading comprehension had trouble to understand the food safety concept [13]. Therefore, the usage of visual-based tools was considered as useful in addressing language and cultural differences [14]. Thus, this study aim to assess the food handlers' knowledge, attitude and practices on personal hygiene in Mamak restaurants before and after poster and video intervention.

\section{EXPERIMENTAL}

\subsection{Study Design and Sample}

This study employed quasi-experimental design of one group pre test-post test. This design allow minimal control of the respondents with assessment being done before and after intervention.100 food handlers (calculated from the sample size formula [15]) were conveniently selected from six 24 hour operated Mamak restaurants in Sungai Petani, Kedah. Respondents must at least have 6 months of working experience in handling food (which may include food and beverage preparation and serving, cooking, washing and cleaning dishes) in the respective restaurants.

\subsection{Assessment Tools}

A set of bi language questionnaire (Bahasa Malaysia and English) was prepared based on the modified questions from previous studies [16-18]. The questionnaire was pre-tested on 10 food handlers in Mamak restaurants in Kajang in order to ensure the consistency of the words and construction. The questionnaire consisted socio demographic variables, knowledge and attitude in relation to personal hygiene.

A standard checklist on personal hygiene constructed by [19] was utilized in order to observe the personal hygiene status of the food handlers.

\subsection{Intervention Tools}

A poster was designed for the purpose of the intervention. The poster illustrated simple 
pictures of a person wearing proper attire for food handling and vice versa. The illustration was accompanied by written and illustration instruction of dos and don'ts during food handling (Fig. 1).

In addition to the poster intervention, an educational video on personal hygiene developed by Ministry of Health was projected to the respondents in order to increase educational experience and level of personal hygiene practices [20]. The video duration was five minutes.

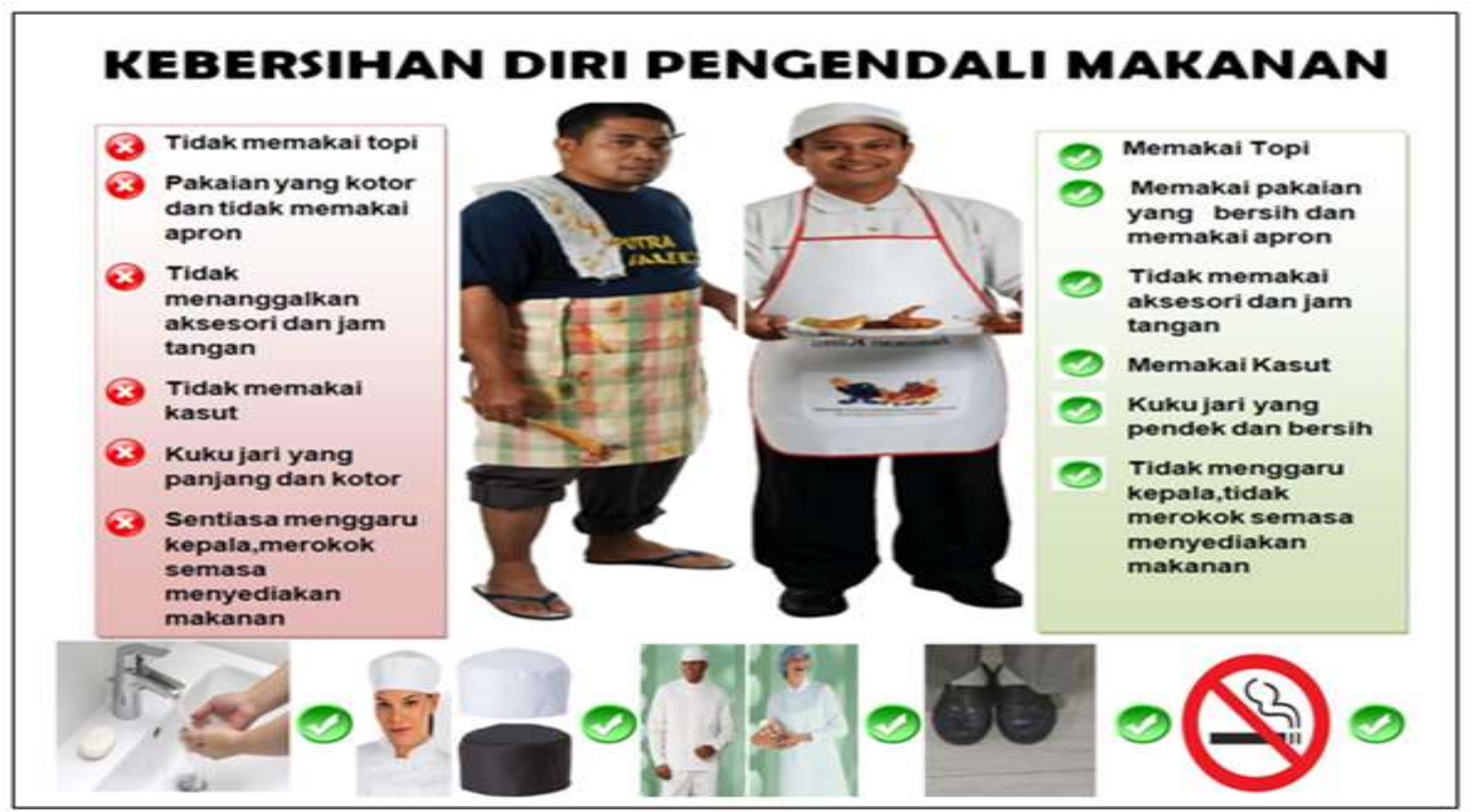

Fig.1. Design of poster for the intervention

\subsection{Study Administration}

The study was collaborated with Sungai Petani Municipal Council. Researcher with the assistance from the environmental health officer entered the premises. At least, four respondents from a premise were selected to answer the questionnaire. The questionnaire was self-administered. An interview session was conducted for respondent who unable to comprehend the languages.

Prior to personal hygiene practices, an observation was done using the standard checklist from [19]. The respondents later were briefed on the personal hygiene, assisted by the educational video adapted from Ministry of Health. Additionally, posters on personal hygiene were placed in the restaurants at designated areas such as food or beverage preparation area, washroom, kitchen and front counter. 
A post evaluation was conducted on the same respondents after four weeks using the similar questionnaire and observation checklist.

\subsection{Data Analysis}

Data were expressed as $\mathrm{n}$ (percentage) for descriptive analysis. Wilcoxon signed ranked was employed in order to compare the Knowledge, Attitude and Practice (KAP) scores at baseline and post intervention. This analysis was expressed as median (interquartile range). A Spearman correlation test was assigned to determine the association within knowledge, attitude and practice on personal hygiene. $p<0.05$ was considered as statistically significant. All data were analyzedusing SPSS version 20.

\section{RESULTS AND DISCUSSION}

Table 1 exhibits the characteristic of the respondents. Most of the respondents were males with age range 20-40 year old and working experience more than a year. $84 \%$ of the respondents reported have attended food safety training.

In relation to level of personal hygiene during baseline and post intervention, the scores obtained for knowledge, attitude and practice (KAP) were categorized into poor and excellent according to the midpoint score calculated. Those who scored above midpoint score were defined as 'Good' whilst below midpoint score indicated as 'Poor'. Table 2 exhibit the percentage of 'Good' and 'Poor' for knowledge, attitude and practice between pre and post intervention. There was an increase of percentage on knowledge and practice during the baseline and post intervention. A slight increase on attitude was observed between pre and post intervention ( $77 \%$ to $100 \%)$. The difference between pre and post intervention scores of KAP was determined using Wilcoxon ranked test (Normality test shown that data were not normally distributed). The result was consistent with the percentage reported whereby there were significantly differences in knowledge and practice scores between baseline and post intervention (see Table 2). The finding is concordant with previous studies [21-22]. This suggests that such training or initiatives are necessary in order to promote appropriate knowledge and practice on food handling [22]. Moreover, the visual-based intervention utilized in this study might be helpful in improving food safety knowledge among the non-natives food handlers [14]. It is also suggested that by incorporating the importance of 
food safety with science-based information may assist the food handlers to understand better and help the health inspectors from being perceived as the 'trouble makers' [14].

In addition to determine any correlation between knowledge on food safety with attitude and knowledge, the result showed insignificant negative weak correlation within the variables $(\mathrm{p}>0.05)$ (Table 3). The result was contradicted with [21, 23] who observed positive correlation between knowledge, attitude and practice. However, the finding demonstrated that knowledge alone does not always result in safe food handling behaviour and this is agreed by [24-25].

Table 1. Respondent socio demographic characteristic $(\mathrm{N}=100)$

\begin{tabular}{cc}
\hline Variables & n (\%) \\
Male & $89(89 \%)$ \\
Female & $11(11 \%)$ \\
\multicolumn{1}{c}{ Age } & \\
$20-30$ & $61(61 \%)$ \\
$30-40$ & $35(35 \%)$ \\
$40-60$ & $4(4 \%)$ \\
Year of Working Experience \\
6 Month \\
1 Years & $9(9 \%)$ \\
2 Years & $16(16 \%)$ \\
3 Years & $18(18 \%)$ \\
$>3$ Years & $17(17 \%)$ \\
Training & $40(40 \%)$ \\
No & $16(16 \%)$ \\
Yes & $84(84 \%)$ \\
\hline
\end{tabular}

Data was presented as $\mathrm{n}(\%)$ for categorical variables. 
Table 2. Level of personal hygiene $(\mathrm{N}=100)$

\begin{tabular}{ccccc}
\hline \multicolumn{4}{c}{ Level of Personal Hygiene, $\mathbf{n}(\%)$} \\
Variable & \multicolumn{2}{c}{ Pre Intervention } & Post Intervention \\
\hline Knowledge & Poor & $: 49(49 \%)$ & Poor & $: 20(20 \%)$ \\
& Good & $: 51(51 \%)$ & Good & $: 80(80 \%)$ \\
Attitude & Poor & $: 23(23 \%)$ & Poor & $: 0(0 \%)$ \\
& Good & $: 77(77 \%)$ & Good & $: 100(100 \%)$ \\
Practice & Poor & $: 58(58 \%)$ & Poor & $: 27(27 \%)$ \\
& Good & $: 42(42 \%)$ & Good & $: 73(73 \%)$ \\
\hline
\end{tabular}

Data was presented as n (\%) for categorical variables.

Table 3. Median scores for knowledge, attitude and practice on personal hygiene during pre

\begin{tabular}{cccc}
\multicolumn{4}{c}{ and post intervention } \\
\hline Variables & \multicolumn{2}{c}{ Median (IQR) } & p-Value \\
& Pre Intervention & Post Intervention & \\
\hline Knowledge & $7.00(7.00)$ & $8.00(7.50)$ & $<0.001^{*}$ \\
Attitude & $7.00(7.00)$ & $7.00(7.00)$ & 0.965 \\
Practice & $4.0(4.50)$ & $6.00(5.50)$ & $<0.001^{*}$ \\
\hline
\end{tabular}

Wilcoxon ranked is used to compare continuous variable. Data is presented as median (IQR). *indicates significant $(\mathrm{p}<0.05)$. IQR: Interquartile range.

Table 4. Correlation between knowledge and attitude; knowledge and practice

\begin{tabular}{cccc}
\hline Variable & & r & p-Value \\
\hline Knowledge & Attitude & -0.009 & 0.93 \\
& Practice & -0.082 & 0.415 \\
\hline
\end{tabular}

Spearman rho is used to correlate continuous data. Data is presented as $r$ coefficient.

\section{CONCLUSION}

Finding from this study indicated that the usage of visual-based intervention was helpful in 
educating the food safety component of personal hygiene among the non-native speaker food handlers, which in this study were the Mamak food handlers. Nevertheless, the incorporation of knowledge, attitude and element in this study predict limited effectiveness of food hygiene intervention. An intervention that imparts health-related behaviours framework such as theory-planned behaviour (TPB) should be warranted for future study. In addition, the employment of one group quasi experimental design was noted to be lacked in internal validity due to the respondent's maturity and selection-history threats. Therefore, a randomized controlled trial designed is proposed in order for the population of participating individuals are clearly identified.

\section{ACKNOWLEDGEMENTS}

The authors would like to express their gratitude to all participants for their contribution and participation throughout the research.

\section{REFERENCES}

[1] Zarina Z, Faisal I.Jommamak! Examining the role of sociocultural and technological determinants in a local pop-culture phenomenon. Selangor: SEGi University, 2012

[2] Lim A. The Mamak phenomenon. 2005, http://www.thingsasian.com/item.html;jsessionid=63FDF1EB5642F39745076AE509BCF0 58 itemId $=1684 \&$ bhId $=2461202 \&$ seIndex $=4$

[3] Wan Z. Celebrating the unity of Malaysians through the Mamak stalls. 2005, http://wanzafran.com/2005/celebrating-the-unity-of-malaysiansthrough-mamak-stalls/ [4] Bernama. 16 premismakanan di KL abaikankebersihandiarahtutup. 2016,http://myputrajayanews.com/v2/16-premis-makanan-di-kl-abaikan-kebersihan-diarah-tut up/

[5] SinarHarian. Tigarestoran di arahtutup.2015, http://www.sinarharian.com.my/edisi/selangor-k1/tiga-restoran-diarah-tutup-1.368227

[6] Planning Division, Health Informatics Centre. MOH annual reports 2004-2013. Ministry of Health Malaysia. 2007, www.moh.gov.my

[7] Ministry of Health Malaysia (MOH) Malaysia. Food safety and quality division: 
Guidelines for accreditation of food handlers training program. 2016, http://fsq.moh.gov.my/v5/ms/garis-panduan-skim-akreditasi-program-latihan-pengendali-mak anan-lpm-3/

[8] Abdul-Mutalib N A, Syafinaz A N, Sakai K, Shirai Y. An overview of food borne illness and food safety in Malaysia. International Food Research Journal, 2015, 22(3):896-901

[9] Soon J M, Singh H, Baines R. Foodborne diseases in Malaysia: A review. Food Control, 2011, 22(6):823-830

[10] Manes M R, Liu L C, Dworkin M S. Baseline knowledge survey of restaurant food handlers in suburban Chicago: Do restaurant food handlers know what they need to know to keep consumers safe? Journal of Environmental Health, 2013, 76(1):18-26

[11] Lynch R A, Elledge B L, Griffith C C, Boatright D T. A comparison of food safety knowledge among restaurant managers, by source of training and experience, in Oklahoma County, Oklahoma. Journal of Environmental Health, 2003, 66(2):9-14

[12] DeBess E E, Pippert E, Angulo F J, Cieslak P R. Food handler assessment in Oregon. Foodborne Pathogens and Disease, 2009, 6(3):329-335

[13]Brown A. Understanding food: Principles and preparation. Massachusetts: CengageLearning, 2014

[14] Dawei L.Development and assessment of visual-based training on Chinese-speaking foodservice workers in independently owned Chinese restaurants.Master thesis,Ames: Iowa State University, 2015

[15] Daniel W. W. Biostatistics: A foundation for analysis in the health sciences. 2009, http://www.ggen.uac.pt/mgen/docs/BIOSTATISTICS_daniel.pdf

[16] Acikel C H, Ogur R, Yaren H, Gocgeldi E, Ucar M, Kir T. The hygiene training of food handlers at a teaching hospital. Food Control, 2008, 19(2):186-190

[17] Gomes-Neves E, Araújo A C, Ramos E, Cardoso C S. Food handling: Comparative analysis of general knowledge and practice in three relevant groups in Portugal. Food Control, 2007, 18(6):707-712

[18] Tokuç B, Ekuklu G, Berberoğlu U, Bilge E, Dedeler H. Knowledge, attitudes and self-reported practices of food service staff regarding food hygiene in Edirne, Turkey. Food Control, 2009, 20(6):565-568 
[19] Ministry of Urban Wellbeing, Housing and Local Government Malaysia.Food premise $\begin{array}{llll}\text { inspection and } \text { grading } & \text { form. }\end{array}$ http://www.mdbg.gov.my/sites/default/files/perniagaan/pelesenan/garis_panduan_sistem_pen ggredan_premis_makanan_di_kawasan_pihak_berkuasa_tempatan.pdf [20] Ministry of Health (MOH) Malaysia. MOH educational video on personal hygiene. 1998, ttps://www.youtube.com/watch?v=ZbBdcd7IGfA

[21] Ansari-Lari M, Soodbakhsh S, Lakzadeh L. Knowledge, attitudes and practices of workers on food hygienic practices in meat processing plants in Fars, Iran. Food Control, 2010, 21(3):260-263

[22] Huda N. Tahappengetahuan, sikapdanamalankebersihandankeselamatanmakanan di kalanganpengendalimakanan di hospital. Master thesis,Selangor: UniversitiKebangsaan Malaysia, 2008

[23] Abdul-Mutalib N A, Abdul-Rashid M F, Mustafa S, Amin-Nordin S, Hamat R A, Osman M. Knowledge, attitude and practices regarding food hygiene and sanitation of food handlers in Kuala Pilah, Malaysia. Food Control, 2012, 27(2):289-293

[24]Mullan B A, Wong C, Kothe E J. Predicting adolescents' safe food handling using an extended theory of planned behavior. Food Control, 2013, 31(2):454-460

[25]Afifi H S, Abushelaibi A A. Assessment of personal hygiene knowledge, and practices in Al Ain, United Arab Emirates. Food Control, 2012, 25(1):249-253

\section{How to cite this article:}

Masyita M, Amalina M J N, Saudi A S M, Samsudin M S, Rizman Z I. Effect of poster and video intervention on the knowledge, attitude and practice (kap) level of personal hygiene among food handlers in 24 hours mamak restaurants in sungai petani, kedah. J. Fundam. Appl. Sci., 2017, 9(4S), 851-860. 